\title{
Identification of factors associated with good response to growth hormone therapy in children with short stature: results from the ANSWER Program $^{\circledR}$
}

Peter A Lee $1^{*}$, John Germak², Robert Gut ${ }^{2}$, Naum Khutoryansky ${ }^{2}$ and Judith Ross ${ }^{3}$

\begin{abstract}
Objective: To identify factors associated with growth in children on growth hormone $(\mathrm{GH})$ therapy using data from the American Norditropin Studies: Web-enabled Research (ANSWER) Program ${ }^{\circledR}$ registry.

Methods: GH-naiive children with GH deficiency, multiple pituitary hormone deficiency, idiopathic short stature, Turner syndrome, or a history of small for gestational age were eligible $(N=1,002)$. Using a longitudinal statistical approach, predictive factors were identified in patients with GHD for change from baseline in height standard deviation score ( $\triangle \mathrm{HSDS})$ following 2 years of treatment.

Results: Gradual increases in $\triangle H S D S$ over time were observed for all diagnostic categories. Significant predictive factors of $\triangle H S D S$, ranked by significance were: height velocity (HV) at 4 months $>$ baseline age $>$ baseline HSDS > baseline body mass index (BMI) SDS > baseline insulin-like growth factor I (IGF-I) SDS; gender was not significant. HV at 4 months and baseline BMI SDS were positively correlated, whereas baseline age, HSDS, and IGF-I SDS were negatively correlated with $\triangle H S D S$.
\end{abstract}

Conclusions: These results may help guide GH therapy based on pretreatment characteristics and early growth response.

\section{Introduction}

Treatment with exogenous growth hormone (GH) has become a well-accepted therapeutic option for children with growth failure. Since the availability of recombinant human GH (rhGH) in 1985, a wide range of conditions associated with decreased growth, including GH deficiency (GHD), Turner syndrome (TS), Noonan syndrome (NS), children born small for gestational age (SGA), Prader-Willi syndrome (PWS), idiopathic short stature (ISS), and SHOX (short stature homeobox) gene haploinsufficiency have been approved by the United States Food and Drug Administration (FDA) for treatment [1-4].

\footnotetext{
* Correspondence: plee@psu.edu

'Department of Pediatrics, Milton S. Hershey Medical Center, Penn State College of Medicine, Hershey, PA, USA

Full list of author information is available at the end of the article
}

Treatment with $\mathrm{GH}$ has been demonstrated to increase both short-term growth and adult height in pediatric patients with a variety of different growth disorders [5-8]. However, considerable variability in response to this treatment has been reported across and within different diagnostic categories [9-11]. Such variability makes decisions about whether to treat with $\mathrm{GH}$, when to begin treatment, and what dosing to use more difficult [12].

Reports from clinical trials and analyses suggest multiple factors that influence the response to $\mathrm{GH}$ treatment. Variables associated with better responses to GH treatment in patients with ISS include first-year growth response, younger age at start of treatment, the difference in height at the start of treatment from target height SD score (HSDS), and GH dose [13,14]. Additional factors may include underlying genetic conditions, 
presence of concomitant illness, and compliance with treatment [15].

Formal height prediction models have been developed that combine information regarding patient- and treatment-related factors. Such prediction models of response to $\mathrm{GH}$ have been developed for patients with isolated or idiopathic GHD [16-20], SGA [21-23], chronic kidney disease [24], ISS [25], and TS [26]. These models have the potential to aid individualized GH treatment planning and the adjustment of therapy based on early responses [27]. However, even though GH treatment regimens can be based on model-derived predictions of growth response [28], existing models account for only about one-half of the variability in the response to GH. Addition of genetic, biochemical, and other new variables to existing models may improve their accuracy and clinical utility $[29,30]$.

Since 2002, the ANSWER (American Norditropin Studies: Web-enabled Research) Program ${ }^{\circledR}$ registry has collected information on patients receiving Norditropin. Participation within the ANSWER Program is at the discretion of the participating physicians and includes diagnostic categories in which treatment with growth hormone is used. The aim of this paper is to report growth response among different diagnostic categories and to identify factors associated with greater growth response over the first 2 years in children with GHD undergoing treatment with $\mathrm{GH}$.

\section{Methods}

\section{Answer program registry}

Data for this analysis were obtained from the ANSWER Program registry, a collection of long-term efficacy and safety information from patients treated with Norditro$\operatorname{pin}^{\circledR}$ (somatropin [rDNA origin] injection, Novo Nordisk A/S, Denmark) [31] in the United States. Patient histories and physical examination data were entered by participating physician investigators using the ANSWER Program registry reporting form, a web-based data entry tool. Informed consent was obtained in all cases. While the registry enrolls GH-treatment-naïve and non-naïve patients, for the purpose of this analysis, only naïve patient data from the following diagnostic categories were included in the current analyses: 1) GHD (isolated/ idiopathic), 2) multiple pituitary hormone deficiency (MPHD), 3) TS, 4) SGA, and 5) ISS.

\section{Study description}

Patient data collected at the first visit and/or follow-up visits included age, gender, GH dose, HSDS, insulin-like growth factor-I (IGF-I) SDS, body mass index (BMI) SDS, bone age, and annualized height velocity (HV). The maximal stimulated serum GH concentration was also recorded. Height and BMI SDS (z scores) were calculated according to the standard formulas provided by the Center for Disease Control and Prevention [32]. IGF-I SDS scores were calculated using a standard algorithm and reference values provided by Diagnostic Systems Laboratories, Inc. (Webster, TX, USA). Data were collected at baseline and at 4 months, 1 year, and 2 years of GH treatment. Data at 4 months were collected within a 1 -month window and data at 1 and 2 years were collected within a 3-month window. To eliminate the potential of erroneous data having been entered, the following rules were used to remove patients from the analysis: lack of height information at baseline, 4 months, 1 year, or 2 years; baseline age 0 or > 18 years; baseline HSDS less than -5 or greater than +2 ; and baseline height $<35 \mathrm{~cm}$ or $>200 \mathrm{~cm}$. Also, patients were excluded when key variables from baseline or subsequent values were deemed physically or chronologically implausible (3.77\% of potential subjects were excluded according to this criteria).

\section{Regression model development}

In this study, a longitudinal statistical approach was used to identify factors that have significant predictive value for change in HSDS from baseline ( $\triangle$ HSDS) in a regression model. $\triangle$ HSDS data collected following the first and second years of treatment were included in the model. A smoothing procedure was applied for the corresponding mean value curves for first-year $\mathrm{HV}$ and baseline age. Due to the limited number of patients in the MPHD, TS, SGA, and ISS diagnostic categories, regression analysis was only performed for patients with GHD. The curves presented were built using polynomial regression. The quadratic polynomial regression, under the assumption that the height SD is not a function of baseline age, provided a sufficient fitting, while higher terms (for example, cubic and fourth degree) were not statistically significant.

\section{Results}

\section{Baseline demographics}

The ANSWER Program registry (as of November 30, 2009) contained information for over 9,000 patients, of which 1,002 GH treatment-naïve patients from selected diagnostic categories (GHD, MPHD, TS, SGA, and ISS) met the criteria for inclusion in this analysis. Baseline demographic characteristics for the subjects in this study by specific diagnostic category are summarized in Table 1. The study included longitudinal data for 698 patients with GHD, 71 with MPHD, 60 with TS, 50 with SGA, and 123 with ISS. Mean baseline ages were lower for MPHD (6.4 years), SGA (7.1 years), and TS (8.5 years) groups compared to those for GHD (10.9 years) or ISS (11.2 years). Baseline mean peak GH levels were lowest for patients with GHD and MPHD (5.5 and 
Table 1 Baseline demographics by diagnostic category

\begin{tabular}{|c|c|c|c|c|c|c|c|c|c|c|}
\hline & \multicolumn{2}{|c|}{ GHD } & \multicolumn{2}{|c|}{ MPHD } & \multicolumn{2}{|c|}{ Turner } & \multicolumn{2}{|r|}{ SGA } & \multicolumn{2}{|r|}{ ISS } \\
\hline & $\mathrm{n}$ & Mean (SD) & $n$ & Mean (SD) & $n$ & Mean (SD) & $n$ & Mean (SD) & $\mathrm{n}$ & Mean (SD) \\
\hline \multicolumn{11}{|l|}{ Gender } \\
\hline Male & 543 & - & 53 & - & 0 & - & 33 & - & 91 & - \\
\hline Female & 155 & - & 18 & - & 60 & - & 17 & - & 32 & - \\
\hline Age & 698 & 10.9 (3.46) & 71 & $6.4(5.23)$ & 60 & $8.5(4.17)$ & 50 & $7.1(3.41)$ & 123 & $11.2(2.88)$ \\
\hline HSDS & 698 & $-2.2(0.86)$ & 71 & $-2.0(1.36)$ & 60 & $-2.5(0.77)$ & 50 & $-2.8(0.97)$ & 123 & $-2.3(0.68)$ \\
\hline IGF-I SDS & 605 & $-2.5(1.26)$ & 31 & $-3.2(1.54)$ & 34 & $-2.0(1.43)$ & 32 & $-2.1(1.53)$ & 114 & $-2.2(1.11)$ \\
\hline BMI SDS & 681 & $-0.1(1.38)$ & 49 & $0.5(1.84)$ & 55 & $0.5(0.97)$ & 49 & $-0.8(1.35)$ & 123 & $-0.8(3.38)$ \\
\hline Bone Age, yrs & 616 & $9.4(3.31)$ & 39 & $8.0(4.58)$ & 43 & $7.8(3.45)$ & 44 & $6.1(3.36)$ & 115 & 9.7 (2.93) \\
\hline Peak GH, ng/mL & 606 & $5.5(2.69)$ & 40 & $3.6(3.03)$ & 5 & $12.5(8.25)$ & 17 & $13.8(10.95)$ & 97 & $15.2(8.10)$ \\
\hline $\mathrm{GH}$ dose, $\mu \mathrm{g} / \mathrm{kg} /$ day & 697 & $45.9(10.1)$ & 71 & $40.6(11.2)$ & 60 & $51.9(9.0)$ & 50 & $49.9(13.5)$ & 123 & $46.1(8.6)$ \\
\hline
\end{tabular}

BMI, body mass index; GH, growth hormone; GHD, growth hormone deficiency; HSDS, height standard deviation score; IGF-I, insulin-like growth factor I; ISS, idiopathic short stature; MPHD, multiple pituitary hormone deficiency; SD, standard deviation; SDS, standard deviation score; SGA, small for gestational age

$3.6 \mathrm{ng} / \mathrm{mL}$, respectively). Baseline mean GH dose ( $\mu \mathrm{g} /$ $\mathrm{kg} /$ day) for the different diagnostic categories was the lowest for MPHD patients, consistent with their apparently greater degree of GH deficiency and associated $\mathrm{GH}$ sensitivity. For all diagnostic categories, the mean and median GH dose did not increase more than 0.007 $\mathrm{mg} / \mathrm{kg} /$ day over the two years, indicating a very narrow $\mathrm{GH}$ dose change over this period.

\section{Height outcomes}

The effects of GH treatment on $\triangle$ HSDS over 2 years of treatment are shown in Table 2. Gradual increases in $\triangle$ HSDS were observed over time and ranged between 0.15 (ISS) to 0.37 (MPHD) at 4 months, and 0.82 (TS) to 1.20 (MPHD) at 2 years, with the largest $\triangle$ HSDS observed at year 1 and year 2 in patients with MPHD and SGA. Annualized HV at 4 months was $13.6 \mathrm{~cm} /$ year for MPHD, and between 8.33 (TS) and 9.96 (SGA) cm/ year for the other indications (Figure 1). Within each diagnostic category, mean annualized HV was the greater during the first year, and generally decreased during the second year. Mean annualized $\mathrm{HV}$ at 1 year was greatest for MPHD at $10.74 \mathrm{~cm} /$ year, and ranged between 7.97 (TS) and 9.57 (GHD) for the other indications.

\section{Regression analysis}

Linear regression was performed on HSDS data for patients with GHD (Table 3). Variables significantly associated with $\triangle$ HSDS 1 and 2 years included HV at 4 months, and baseline age, HSDS, BMI SDS, and IGF-I SDS. The ranking of importance of predictive factors as related to $\triangle$ HSDS (as determined by the $\mathrm{F}$ value, the higher the more influential) was as follows: $\mathrm{HV}$ at 4 months > baseline age > baseline HSDS > baseline BMI SDS $>$ baseline IGF-I SDS. HV at 4 months and baseline BMI SDS were positively correlated with $\triangle$ HSDS, while baseline age, HSDS, and IGF-I SDS were negatively correlated with $\triangle$ HSDS. Gender was less influential than the above factors (Table 3) and was not detected as statistically significant in this analysis.

Table 2 HSDS and $\triangle$ HSDS by diagnostic category

\begin{tabular}{|c|c|c|c|c|}
\hline & \multicolumn{2}{|c|}{ HSDS } & \multicolumn{2}{|c|}{$\Delta \mathrm{HSDS}$} \\
\hline & $n$ & Mean (SD) & $n$ & Mean (SD) \\
\hline \multicolumn{5}{|l|}{ GHD } \\
\hline Baseline & 698 & $-2.22(0.86)$ & - & - \\
\hline 4 Months & 698 & $-2.03(0.82)$ & 698 & $0.19(0.33)$ \\
\hline Year 1 & 698 & $-1.61(0.83)$ & 698 & $0.61(0.49)$ \\
\hline Year 2 & 697 & $-1.17(0.88)$ & 697 & $1.06(0.64)$ \\
\hline \multicolumn{5}{|l|}{ MPHD } \\
\hline Baseline & 71 & $-1.98(1.36)$ & - & - \\
\hline 4 Months & 70 & $-1.62(1.30)$ & 70 & $0.37(0.68)$ \\
\hline Year 1 & 70 & $-1.13(1.04)$ & 70 & $0.85(0.76)$ \\
\hline Year 2 & 70 & $-0.79(1.04)$ & 70 & $1.20(1.04)$ \\
\hline \multicolumn{5}{|l|}{ Turner } \\
\hline Baseline & 60 & $-2.49(0.77)$ & - & - \\
\hline 4 Months & 59 & $-2.32(0.82)$ & 59 & $0.18(0.20)$ \\
\hline Year 1 & 60 & $-1.99(0.86)$ & 60 & $0.50(0.31)$ \\
\hline Year 2 & 60 & $-1.68(0.90)$ & 60 & $0.82(0.43)$ \\
\hline \multicolumn{5}{|l|}{ SGA } \\
\hline Baseline & 50 & $-2.76(0.97)$ & - & - \\
\hline 4 Months & 50 & $-2.48(0.88)$ & 50 & $0.28(0.47)$ \\
\hline Year 1 & 50 & $-1.96(0.93)$ & 50 & $0.80(0.59)$ \\
\hline Year 2 & 50 & $-1.59(1.00)$ & 50 & $1.18(0.65)$ \\
\hline \multicolumn{5}{|l|}{ ISS } \\
\hline Baseline & 123 & $-2.31(0.68)$ & - & - \\
\hline 4 Months & 123 & $-2.16(0.69)$ & 123 & $0.15(0.19)$ \\
\hline Year 1 & 123 & $-1.77(0.69)$ & 123 & $0.54(0.38)$ \\
\hline Year 2 & 123 & $-1.41(0.79)$ & 123 & $0.90(0.59)$ \\
\hline
\end{tabular}

GHD, growth hormone deficiency; HSDS, height standard deviation score; ISS, idiopathic short stature; MPHD, multiple pituitary hormone deficiency; SD, standard deviation; SGA, small for gestational age. 


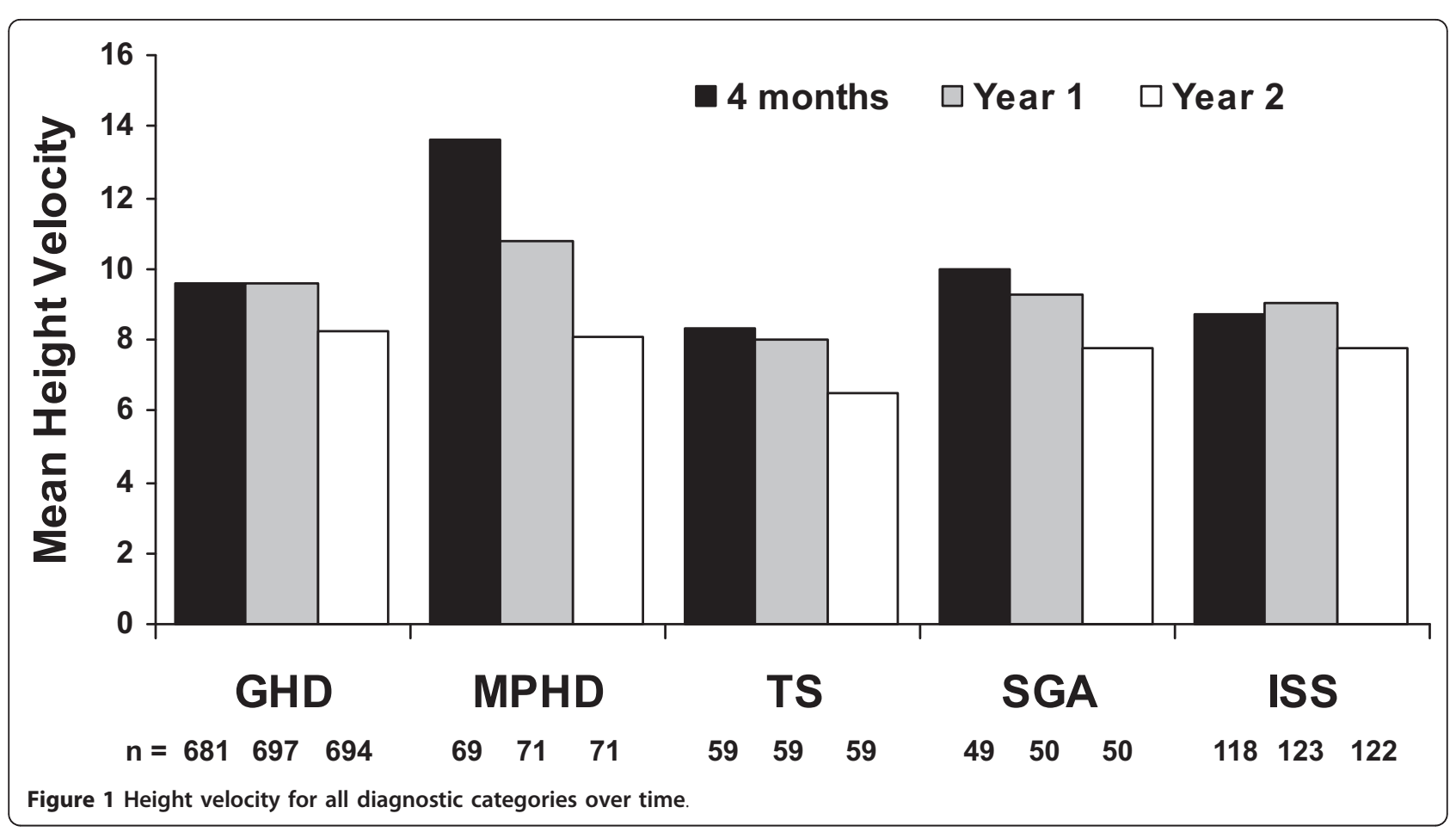

Analysis of the mean values was used to build smoothed curves for demonstration of the relationship between first-year $\triangle$ HSDS and baseline age (Figure 2A and $2 \mathrm{~B}$ ), and between first-year HV and baseline age (Figure $2 \mathrm{C}$ and $2 \mathrm{D}$ ) in male and female patients with GHD. Generally, the curves demonstrate that younger baseline age is associated with greater $\triangle$ HSDS and HV in these patients. Similar curves were observed with male and female patients for both $\triangle$ HSDS and first-year HV.

\section{Discussion}

In this longitudinal study of GH treatment in patients with GHD, MPHD, TS, SGA, and ISS, HSDS improved over time. For patients with GHD, several variables were identified that correlated with growth response during the first and second years of GH treatment. HV at 4

Table 3 Regression model for longitudinal $\triangle H S D S$ at year 1 and year 2 for patients with GHD ( $n=698)$.

\begin{tabular}{lccc}
\hline Characteristic & $\boldsymbol{\beta}$ Estimate & $\boldsymbol{F}$ Value & $\boldsymbol{P}$ Value \\
\hline Height velocity at 4 months & 0.0319 & 214.31 & $<.0001$ \\
Baseline age & -0.0439 & 74.17 & $<.0001$ \\
Baseline HSDS & -0.0776 & 29.11 & $<.0001$ \\
Baseline BMI SDS & 0.0398 & 20.62 & $<.0001$ \\
Baseline IGF-I SDS & -0.0245 & 5.74 & .0169 \\
Gender & -0.0438 & 2.46 & .1175 \\
\hline
\end{tabular}

BMI, body mass index; GHD, growth hormone deficiency; HSDS, height standard deviation score; IGF-I, insulin-like growth factor I; SDS, standard deviation score. months was the most significant predictor of $\triangle$ HSDS observed in the first 2 years of GH treatment. This observation that 4-month HV was such a strong predictor is a novel finding, since many studies do not consistently report growth this early in the treatment cycle. Additional factors that were influential in predicting HSDS outcomes were ranked in order of importance: younger baseline age $>$ lower baseline HSDS > higher baseline BMI SDS > lower baseline IGF-I SDS.

For the GHD patient population, age and baseline HSDS were important determinants of the response to GH treatment, as previously demonstrated $[18,20]$. However, other reports have also indicated additional significant factors, such as birth weight SDS and GH dose [20]. The present results also indicated that higher baseline BMI was positively correlated with the growth response to GH for patients with GHD. Birth weight SDS and weight SDS were shown to be correlated with growth response to $\mathrm{GH}$ in the Pharmacia Kabi International Growth Study, suggesting that the heavier the child was, the greater the expected growth response to $\mathrm{GH}$ treatment [20]. The impact of BMI in this study might reflect, at least in part, the importance of nutrition for optimization of outcomes in patients receiving GH $[1,33]$.

In general, the results from this analysis are consistent with previously published results for specific patient populations. A prior prediction study in patients with TS indicated that first-year growth response to $\mathrm{GH}$ was 


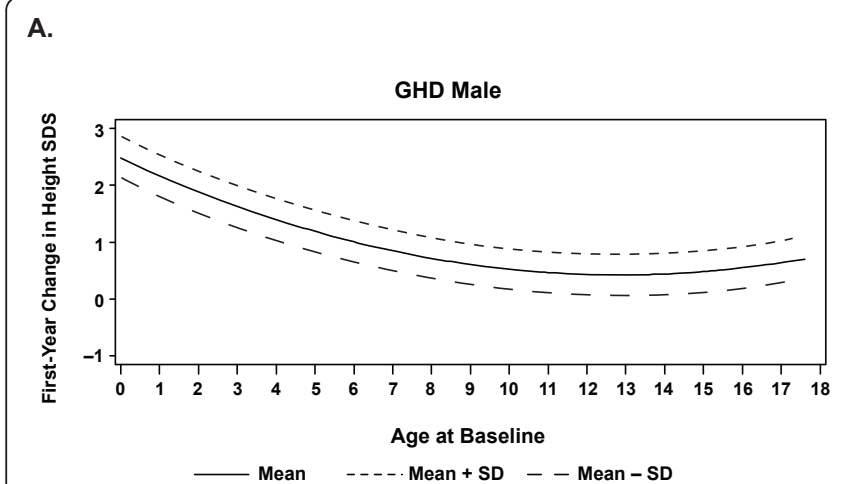

C.

GHD Male

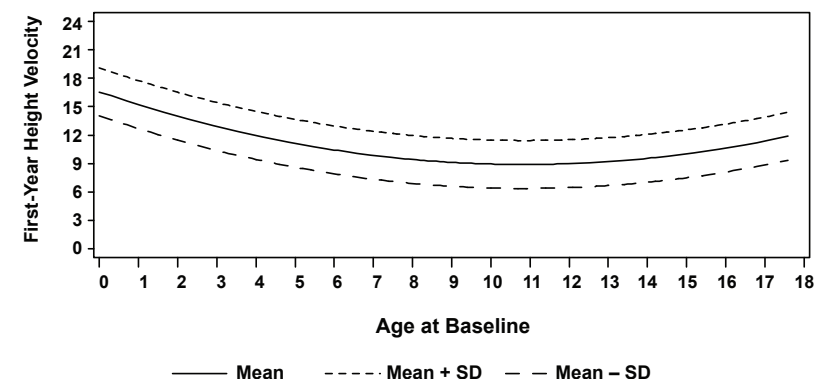

B.

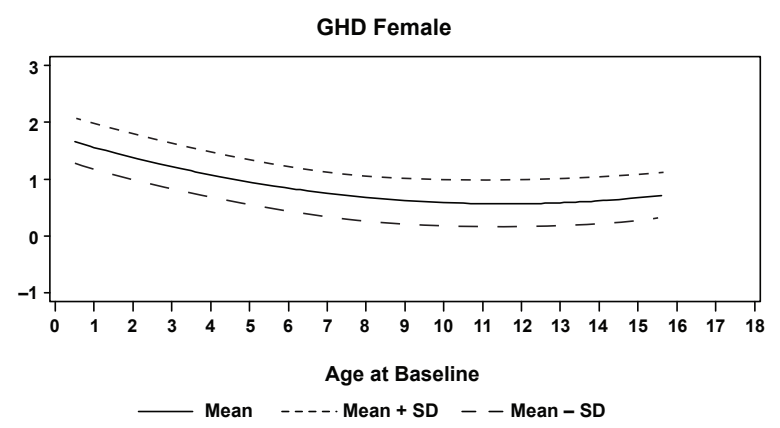

D.

GHD Female

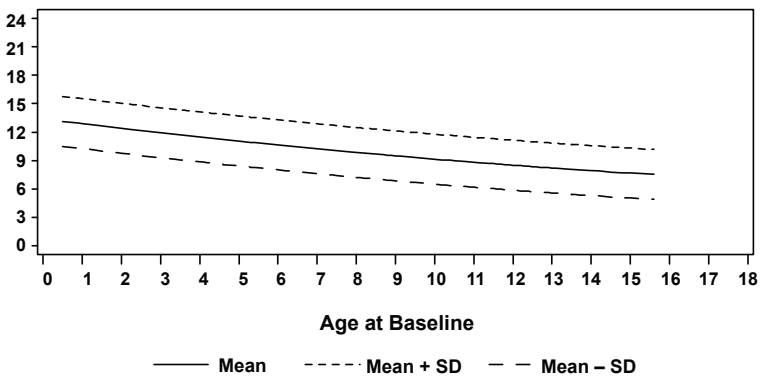

Figure 2 First-year change from baseline HSDS and height velocity vs baseline age for patients with GHD (A, Change in baseline HSDS in male patients with GHD; B, Change in baseline HSDS in female patients with GHD; C, Change in height velocity in male patients with GHD; D, Change in height velocity in female patients with GHD).

significantly influenced by weekly GH dose, chronological age, HSDS, body weight SDS, number of GH injections per week, and adjunctive oxandrolone treatment [26]. Predictors of the growth response over a longer duration of treatment (2-4 years) included HV during previous years, weekly GH dose, weight SDS, age, and oxandrolone treatment [26]. In SGA patients, results from one study found that first-year growth response to GH treatment was the most important predictor of second-year growth response [21]. Other variables that were significantly correlated with the growth response to GH included GH dose, weight and age at the start of treatment, and midparental HSDS [21]. Studies in the ISS patient population have identified additional factors as predictors of longer-term responses to $\mathrm{GH}$, including baseline HSDS, GH dose, weight at the start of treatment, and first-year growth response [13,14]. It is important to recognize that this category may be the most heterogenous, with growth failure being a consequence of many different etiologies.

Specific results from other studies that are consistent with the present analysis, include the lack of gender effect on response to GH treatment. Analysis of results from the Pfizer Kabi International Growth Study database found no significant gender-related differences in effects of GH in HV or HSDS over 2 or 3 years of treatment [34]. In 8,018 patients with ISS in the National Cooperative Growth Study there was no significant effect of gender on first-year HV or first-year change from baseline in height SDS [35]. In a recent report, a large cohort of male and female patients with GHD, MPHD, TS, SGA, NS, and ISS from the ANSWER Program registry was used to assess gender-related differences in $\triangle$ HSDS following 2 years of GH treatment. Results demonstrated increased $\triangle$ HSDS in all patients, however, clinically relevant gender differences were not observed [36]. The importance of early timing for initiation of treatment from the present analysis is also consistent with previous findings. A National Registry of Growth Hormone Treatment report in the Netherlands that included 342 patients (diagnosis of GHD or a maximal GH response during provocation tests of less than $11 \mathrm{ng} / \mathrm{mL}$ ) indicated that initiation of treatment before puberty resulted in a change from baseline in HSDS of 0.71 vs 0.58 for those who initiated treatment after puberty [19]. Results from the French registry of 2,852 patients with idiopathic GHD also indicated that prepubertal initiation of GH treatment was associated with significantly greater adult height gain [37]. Although in this study it is not known what proportion of patients 
across the different diagnostic categories may have been in puberty, the mean baseline chronological and bone ages are consistent with the majority of patients being prepubertal, and this likely lessens the impact of puberty on the observed growth responses.

The different correlations between baseline age, HSDS, BMI SDS, and IGF-I SDS, with growth response over 2 years of treatment with $\mathrm{GH}$, carry implications for clinical practice. The correlation of baseline age with $\triangle$ HSDS and HV in the patients with GHD further support the initiation of $\mathrm{GH}$ at as young an age as possible to promote optimal growth. This concept is supported by results from another study that demonstrated a relationship between baseline age and first-year HV for patients with GHD, MPHD, and TS [15]. Several consensus statements endorse the use of $\mathrm{GH}$ treatment as soon as a diagnosis is made or growth failure is demonstrated for patients from several diagnostic categories [38-41]. The inverse relationship observed between baseline IGF-I and the two-year change in HSDS is consistent with an increased sensitivity to the effects of $\mathrm{GH}$ in patients who have a greater degree of GHD. In this non-interventional observational study, serum IGF-I was measured at a number of commercial laboratories reflecting routine clinical practice. IGF-I SDS was calculated using one formula which provided consistency to the analysis. This is also reflected in the finding that mean baseline IGF-I SDS in both the GHD and MPHD populations was lower than that observed in non-GHD patients. The positive correlation observed between baseline BMI SDS and $\triangle$ HSDS may emphasize the importance of nutrition in patients with growth failure $[33,40]$. An abnormally low BMI in pediatric patients may be a sign of malnutrition, which can also be associated with growth disturbances. In the end, the role of baseline age, HSDS, BMI SDS, and IGF-I SDS in the response of individual patients to GH therapy should all be considered for optimal management of short stature or growth failure.

\section{Conclusion}

The present results from a large patient cohort enrolled in the ANSWER Program registry demonstrate gradual increases in $\triangle$ HSDS over time for all diagnostic categories. For patients with GHD, greater HV at 4 months is the most significant predictor of $\triangle \mathrm{HSDS}$ over the first 2 years of GH treatment, while gender did not have any influence.

\section{Acknowledgements}

The authors would like to thank Bob Rhoads, PhD and Jennifer R. Kent, PhD, of MedVal Scientific Information Services, LLC, for providing writing and editorial assistance. Funding to support the preparation of this manuscript was provided by Novo Nordisk, Inc. Data from this paper were presented at the 49th Annual Meeting of the European Society for Paediatric Endocrinology (ESPE) in Prague, Czech Republic, 22-25 September 2010.

\section{Author details}

${ }^{1}$ Department of Pediatrics, Milton S. Hershey Medical Center, Penn State College of Medicine, Hershey, PA, USA. ${ }^{2}$ Novo Nordisk Inc, Princeton, NJ, USA. ${ }^{3}$ Department of Pediatrics, Thomas Jefferson University duPont Hospital for Children, Philadelphia, PA, USA.

\section{Authors' contributions}

All authors contributed equally to this work and were involved in determining the study concept and design as well as providing data analysis and interpretation. RG and JG provided access to the registry data. NK performed the regression analysis. At all stages, the authors discussed the results and implications of the data and commented on the manuscript. All authors read and approved the final manuscript."

\section{Competing interests}

PAL is a consultant for Abbott and Novo Nordisk, and has received clinical study support from Abbott, Novo Nordisk, Eli Lilly, Pfizer, and Ipsen. JR is a consultant for Novo Nordisk and Eli Lilly, and has received clinical study support from Novo Nordisk, Eli Lilly, and Pfizer. JG, RG, and NK are employees of Novo Nordisk.

Received: 16 June 2011 Accepted: 7 July 2011 Published: 7 July 2011

\section{References}

1. Grumbach MM, Bin-Abbas BS, Kaplan SL: The growth hormone cascade: progress and long-term results of growth hormone treatment in growth hormone deficiency. Horm Res 1998, 49(suppl 2):41-57.

2. Mazzanti L, Tamburrino F, Bergamaschi R, Scarano E, Montanari F, Torella M, Ballarini E, Cicognani A: Developmental syndromes: growth hormone deficiency and treatment. Endocr Dev 2009, 14:114-134.

3. Harris M, Hofman PL, Cutfield WS: Growth hormone treatment in children: review of safety and efficacy. Paediatr Drugs 2004, 6:93-106.

4. Richmond $E$, Rogol AD: Current indications for growth hormone therapy for children and adolescents. Endocr Dev 2010, 18:92-108.

5. Bryant J, Baxter L, Cave CB, Milne R: Recombinant growth hormone for idiopathic short stature in children and adolescents. Cochrane Database Syst Rev 2007, CD004440.

6. Baxter L, Bryant J, Cave CB, Milne R: Recombinant growth hormone for children and adolescents with Turner syndrome. Cochrane Database Syst Rev 2007, CD003887.

7. Maiorana A, Cianfarani S: Impact of growth hormone therapy on adult height of children born small for gestational age. Pediatrics 2009, 124: e519-e531.

8. Crabbe R, von HM, Engrand P, Chatelain P: Recombinant human growth hormone for children born small for gestational age: meta-analysis confirms the consistent dose-effect relationship on catch-up growth. $J$ Endocrinol Invest 2008, 31:346-351.

9. Pasquino AM, Passeri F, Municchi G, Segni M, Pucarelli I, Larizza D, Bossi G, Severi F, Galasso C: Final height in Turner syndrome patients treated with growth hormone. Horm Res 1996, 46:269-272.

10. Ranke MB, Lindberg A, KIGS International Board: Height at start, first-year growth response and cause of shortness at birth are major determinants of adult height outcomes of short children born small for gestational age and Silver-Russell syndrome treated with growth hormone: analysis of data from KIGS. Horm Res Paediatr 2010, 74:259-266.

11. Sas TC, de Ridder MA, Wit JM, Rotteveel J, Oostdijk W, Reeser HM, Otten BJ, de Muinck Keizer-Schrama SM: Adult height in children with growth hormone deficiency: a randomized, controlled, growth hormone doseresponse trial. Horm Res Paediatr 2010, 74:172-181.

12. Hintz RL: Growth hormone treatment of idiopathic short stature: clinical studies. Growth Horm IGF Res 2005, 15(suppl A):S6-S8.

13. Zucchini S: Growth hormone use in the treatment of idiopathic short stature. Curr Opin Invest Drugs 2008, 9:396-401.

14. Ranke MB, Lindberg A, Price DA, Darendeliler F, bertsson-Wikland K, Wilton P, Reiter EO: Age at growth hormone therapy start and first-year responsiveness to growth hormone are major determinants of height outcome in idiopathic short stature. Horm Res 2007, 68:53-62. 
15. Bakker B, Frane J, Anhalt H, Lippe B, Rosenfeld RG: Height velocity targets from the national cooperative growth study for first-year growth hormone responses in short children. J Clin Endocrinol Metab 2008, 93:352-357.

16. Lechuga-Sancho A, Lechuga-Campoy JL, del Valle-Nunez J, Rivas-Crespo F: Predicting the growth response of children with idiopathic growth hormone deficiency to one year of recombinant growth hormone treatment: derivation and validation of a useful method. J Pediatr Endocrinol Metab 2009, 22:501-509.

17. Land C, Blum WF, Shavrikova E, Kloeckner K, Stabrey A, Schoenau E: Predicting the growth response to growth hormone $(\mathrm{GH})$ treatment in prepubertal and pubertal children with isolated GH deficiency-model validation in an observational setting (GeNeSIS). J Pediatr Endocrinol Metab 2007, 20:685-693.

18. Sudfeld H, Kiese K, Heinecke A, Bramswig JH: Prediction of growth response in prepubertal children treated with growth hormone for idiopathic growth hormone deficiency. Acta Paediatr 2000, 89:34-37.

19. de Ridder MA, Stijnen T, Hokken-Koelega AC: Prediction of adult height in growth-hormone-treated children with growth hormone deficiency. J Clin Endocrinol Metab 2007, 92:925-931.

20. Ranke MB, Lindberg A, Chatelain P, Wilton P, Cutfield W, bertssonWikland K, Price DA: Derivation and validation of a mathematical model for predicting the response to exogenous recombinant human growth hormone $(\mathrm{GH})$ in prepubertal children with idiopathic GH deficiency. KIGS International Board. Kabi Pharmacia International Growth Study. J Clin Endocrinol Metab 1999, 84:1174-1183.

21. Ranke MB, Lindberg A, Cowell CT, Wikland KA, Reiter EO, Wilton P, Price DA: Prediction of response to growth hormone treatment in short children born small for gestational age: analysis of data from KIGS (Pharmacia International Growth Database). J Clin Endocrinol Metab 2003, 88:125-131.

22. de Zegher F, Albertsson-Wikland K, Wollmann HA, Chatelain P, Chaussain JL, Lofstrom A, Jonsson B, Rosenfeld RG: Growth hormone treatment of short children born small for gestational age: growth responses with continuous and discontinuous regimens over 6 years. J Clin Endocrinol Metab 2000, 85:2816-2821.

23. Dahlgren J, Kristrom B, Niklasson A, Nierop AF, Rosberg S, AlbertssonWikland $\mathrm{K}$ : Models predicting the growth response to growth hormone treatment in short children independent of $\mathrm{GH}$ status, birth size and gestational age. BMC Med Inform Decis Mak 2007, 7:40.

24. Mehls O, Lindberg A, Nissel R, Haffner D, Hokken-Koelega A, Ranke MB: Predicting the response to growth hormone treatment in short children with chronic kidney disease. J Clin Endocrinol Metab 2010, 95:686-692.

25. Spagnoli A, Spadoni GL, Boscherini B: Preliminary validation of a prediction model for the short-term growth response to growth hormone therapy in children with idiopathic short stature. Acta Paediatr Supp/ 1996, 417:66-68.

26. Ranke MB, Lindberg A, Chatelain P, Wilton P, Cutfield W, bertssonWikland K, Price DA: Prediction of long-term response to recombinant human growth hormone in Turner syndrome: development and validation of mathematical models. KIGS International Board. Kabi International Growth Study. J Clin Endocrinol Metab 2000, 85:4212-4218.

27. Ranke MB: New paradigms for growth hormone treatment in the $21 \mathrm{st}$ century: prediction models. J Pediatr Endocrinol Metab 2000, 13(suppl 6):1365-1369.

28. Ranke MB, Lindberg $A$ : Observed and predicted growth responses in prepubertal children with growth disorders: guidance of growth hormone treatment by empirical variables. J Clin Endocrinol Metab 2010, 95:1229-1237.

29. Geffner ME, Dunger DB: Future directions: growth prediction models. Horm Res 2007, 68(suppl 5):51-56.

30. Ranke MB, Lindberg $A$ : Predicting growth in response to growth hormone treatment. Growth Horm IGF Res 2009, 19:1-11.

31. Novo Nordisk: Norditropin cartridges (somatropin [rDNA origin] injection) for subcutaneous use [prescribing information]. Princeton, NJ; 2010.

32. US Centers for Disease Control and Prevention: Percentile data files with LMS values.[http://www.cdc.gov/growthcharts/percentile_data_files.htm].

33. Farber RS, Kerrigan JR: The multiple indications for growth hormone treatment of pediatric patients. Pediatr Ann 2006, 35:926-932.

34. Rose SR, Shulman DI, Larsson P, Wakley LR, Wills S, Bakker B: Gender does not influence prepubertal growth velocity during standard growth hormone therapy-analysis of United States KIGS data. J Pediatr Endocrinol Metab 2005, 18:1045-1051.

35. Kemp SF, Kuntze J, Attie KM, Maneatis T, Butler S, Frane J, Lippe B: Efficacy and safety results of long-term growth hormone treatment of idiopathic short stature. J Clin Endocrinol Metab 2005, 90:5247-5253.

36. Ross J, Lee PA, Gut R, Germak J: Factors influencing the one- and twoyear growth response in children treated with growth hormone: analysis from an observational study. Int J Pediatr Endocrinol 2010, 2010:494656.

37. Carel JC, Ecosse E, Nicolino M, Tauber M, Leger J, Cabrol S, Bastie-Sigeac I, Chaussain $\mathrm{J}$, Coste $\mathrm{J}$ : Adult height after long term treatment with recombinant growth hormone for idiopathic isolated growth hormone deficiency: observational follow up study of the French population based registry. BMJ 2002, 325:70.

38. Cohen P, Rogol AD, Deal CL, Saenger P, Reiter EO, Ross JL, Chernausek SD, Savage MO, Wit JM: Consensus statement on the diagnosis and treatment of children with idiopathic short stature: a summary of the Growth Hormone Research Society, the Lawson Wilkins Pediatric Endocrine Society, and the European Society for Paediatric Endocrinology Workshop. J Clin Endocrinol Metab 2008, 93:4210-4217.

39. Lee PA, Chernausek SD, Hokken-Koelega AC, Czernichow P: International Small for Gestational Age Advisory Board consensus development conference statement: management of short children born small for gestational age, April 24-October 1, 2001. Pediatrics 2003, 111:1253-1261.

40. Growth Hormone Research Society: Consensus guidelines for the diagnosis and treatment of growth hormone $(\mathrm{GH})$ deficiency in childhood and adolescence: summary statement of the GH Research Society. GH Research Society. J Clin Endocrinol Metab 2000, 85:3990-3993.

41. Bondy CA: Care of girls and women with Turner syndrome: A guideline of the Turner Syndrome Study Group. J Clin Endocrinol Metab 2007, 92:10-25.

doi:10.1186/1687-9856-2011-6

Cite this article as: Lee et al:: Identification of factors associated with good response to growth hormone therapy in children with short stature: results from the ANSWER Program ${ }^{\circledR}$. International Journal of Pediatric Endocrinology 2011 2011:6.

\section{Submit your next manuscript to BioMed Central and take full advantage of:}

- Convenient online submission

- Thorough peer review

- No space constraints or color figure charges

- Immediate publication on acceptance

- Inclusion in PubMed, CAS, Scopus and Google Scholar

- Research which is freely available for redistribution

Submit your manuscript at www.biomedcentral.com/submit
C Biomed Central 